\title{
Editorial-Despite Gardasil 9 Success Not Reached in Complete Eradication of High Risk Human Papilloma Virus-What is the Next Step for Cervical, Oropharyngeal Cancers Prevention
}

\section{Kulvinder Kochar Kaur*}

Scientific Director, Centre for Human Reproduction, Jalandhar, Punjab, India

*Corresponding Author: Kulvinder Kochar Kaur, Scientific Director, Centre for Human Reproduction, Jalandhar, Punjab, India.

DOI: $10.31080 /$ ASCB.2020.04.0206
Received: January 31, 2020

Published: February 01, 2020

(c) All rights are reserved by Kulvinder

Kochar Kaur.
We reviewed earlier the importance of human papilloma virus (HPV), in Cervical Cancer development with role of various viral proteins, as well as oropharyngeal cancer [1-2]. Although $90 \%$ of HPV infections get cleared within $2 y r s$ without need for medical treatment, persistent infections with HPV's at high risk (HR- HPV's) can progress to cancer. Low risk HPV (LR HPV) usually don't cause cancers but get correlated with genital warts as well as respiratory papillomatosis $[3,4]$. Besides that other proof correlated HPV with vaginal, vulvar penile, anal along with oropharyngeal Cancer particularly tonsillar, as well as base of tongue [4].

In 2008 - 2010 cervical HPV prevalence (69.5\%) as well as HPV 16 prevalence $(34.7 \%)$ was $>$ in nonvaccinated women at a youth clinic in Stockholm 2013 - 2015 following quadrivalent-Gardasil( ${ }^{(R)}$ HPV vaccine introduction, reduction of HPV 16 as well as HPV 6 prevalence took place. Thus Ahrlund-Richter., et al. evaluated the cervical HPV prevalence 10yrs following primary sampling. In 2017 - 2018, 178 cervical swabs among women 15 - 23 yrs age, were evaluated for 27 HPV kinds utilizing bead based multiplex method. HPV prevalence data was associated with vaccination status and age as compared to HPV prevalence in 615 samples from 2008 - 2010 as well as 338 from 2013 to 2015 from the same clinic, as well as to HPV kinds in 143 cervical cancer cases during 2003 to 2008 in Stockholm, Percentage of vaccinated women enhanced from 10.7\% (2008 - 2010) to 82.1\% (2017 - 2018).Prevalence of all 27 HPV's at high risk (HR - HPV's) as well as combined presence of quadrivalent - Gardasil ${ }^{(\mathrm{R})}$ types HPV 16,18,6 and 11 was lower in vaccinated as compared to nonvaccinated women $67.4 \%$ vs $93.3 \%, \mathrm{p}=0.0031,60.1$ vs $86.7 \%, \mathrm{p}=0.0057$ and 5.8 vs $26.7 \%, \mathrm{p}$ $=0.002$,respectively).Moreover HPV 16 prevalence in nonvaccinated women 2017-2018 was lower than those in $2008-2010$ $(16.7 \%$ and $34.7 \%$ respectively, $\mathrm{p}=0.0471)$ with similar trends were seen towards HPV 18 as well as 11,Within both vaccinated as well as nonvaccinated women, the commonest non quadrivalent -Gardasil ${ }^{(\mathrm{R})}$ vaccine HR- HPV's types were HPV 39,51,52,56 as well as 59. Overall these represented roughly $9.8 \%$ of cervical cancer cases in Stockholm during 2003 - 2008, with their prevalence having a tendency to rise during 2017 - 2018 as compared to 2008 2010.Thus quadrivalent -Gardasil ${ }^{(\mathrm{R})}$ vaccination has reduced HPVvaccine type prevalence significantly. But, nonvaccine HR - HPV's types continue to be high in potentially HR women at a youth clinic in Stockholm [5]. Gardasil ${ }^{(\mathrm{R})} 9$ is the latest HPV vaccine, covering HPV 6,16,18,31,33,45, 52 as well as 58 [6]. It includes HPV 52 but not the other 4 HPV 39,51,56 as well as 59 observed in 2017 - 2018 clinic although it does include 5/6common HR-HPV-16,18,33,45 and 56 found in 2003 to 2008 in Stockholm [7]. One needs to cautiously note irrespective of rise in HPV $39,51,52,56$ as well as 59as they accounted for $9.8 \%$ of Cancer cervix in 2003 to 2008 in Stockholm [7]. Thus despite reduction in 4 HR- HPV's16,18,6 and 11,5 non vaccine specific HR- HPV's39,51,52,56 and 59 remain high in potentially HR- HPV's of these one only (52) is included in Gardasil $^{(\mathrm{R})}$ 9. Thus important is to follow up most HPV prevalent type in next generation of HPV vaccines (Figure1 and 2).

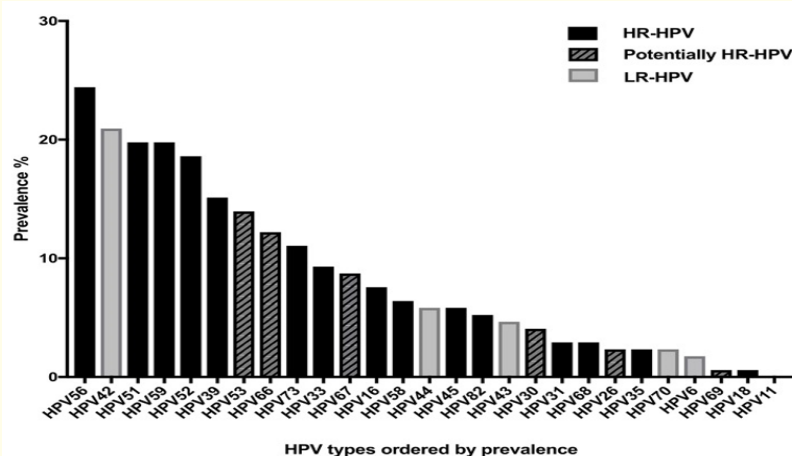

Figure 1: Courtesy ref no-5-Cervical human papillomavirus (HPV) prevalence of all tested HPV types irrespective of vaccination status.

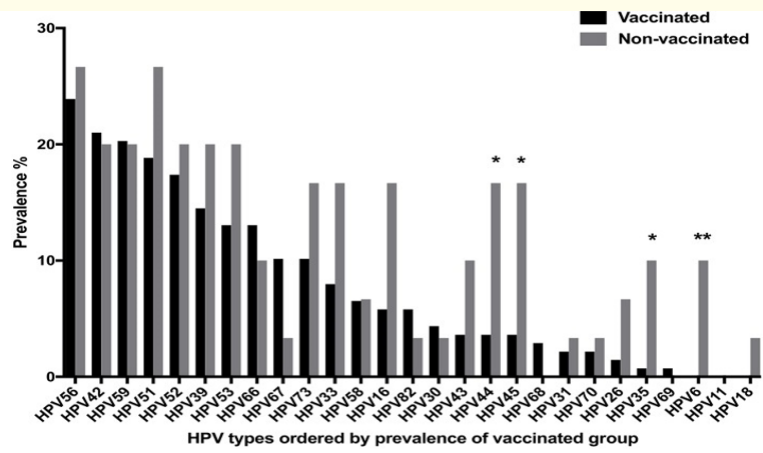

Figure 2: Courtesy ref no-5-Cervical human papillomavirus (HPV) prevalence of all tested HPV types according to vaccination status (Vaccinated or non-vaccinated). ${ }^{*} p<0.05,{ }^{* *} p<0.01$. 


\section{Bibliography}

1. Kulvinder Kochar Kaur., et al. "A Systematic Review of Aetiopathogenesis of Cervical Cancer Development-Role of HPV, Cervical Cancer Stem Cells and Micro RNA and Utilizing these as Novel Targets for Treatment - An Update". Acta Scientific Cancer Biology 3.11 (2019): 28-37.

2. Kulvinder Kochar Kaur., et al. "HPV Related Disease and Cancers-Increased incidence of HPV-Positive Oropharyngeal Cancers". Acta Scientific Microbiology 2.72 .7 (2019): 1-4.

3. Ho GY., et al. "Natural history of cervicovaginal papillomavirus infection in young women". The New England Journal of Medicine 338 (1998): 423-428.

4. Tommasino M. "The human papillomavirus family andits role in carcinogenesis". Seminars in Cancer Biology 26 (2014): 1321.

5. Ahrlund-Richter A., et al. "Changes in Cervical human papilloma virus (HPV), prevalence at a youth clinic in Stockholm, Sweden, a Decade After the Introduction of the HPV Vaccine". Frontiers in Cellular and Infection Microbiology 9 (2019): 59.

6. Schiller J and Lowy D. "Explanations for the high potencyof HPV prophylactic vaccines". Vaccine 36.32 (2018): 4768-4773.

7. Du J., et al. "Prevalence of human papillomavirus (HPV) types in cervical cancer 2003-2008 in Stockholm, Sweden, before public HPV vaccination". Acta Oncologica 50 (2011): 12151219.

\section{Assets from publication with us}

- Prompt Acknowledgement after receiving the article

- Thorough Double blinded peer review

- Rapid Publication

- Issue of Publication Certificate

- High visibility of your Published work Website: https://www.actascientific.com/ Submit Article: https://www.actascientific.com/submission.php Email us: editor@actascientific.com

Contact us: +91 9182824667 